\title{
Pulmoner Kapak Yokluğu Sendromu: Olgu Serisi
}

\author{
Absent Pulmonary Valve Syndrome: Case Series
}

\author{
Oya DEMIRCI *, Taner YAVUZ **, Emre ERDOĞDU * \\ Resul ARISOY *, Pınar KUMRU *, Oya PEKİN *, Bülent TANDOĞAN *
}

(*) Zeynep Kamil Kadın ve Çocuk Hastalıkları Eğt. ve Araştırma Hastanesi, Perinatoloji Kliniği, İstanbul, Türkiye. $\left.{ }^{(* *}\right)$ Zeynep Kamil Kadın ve Çocuk Hastalıkları Eğt. ve Araştırma Hast., Çocuk Kardiyoloji Kliniği, İstanbul, Türkiye.

\section{$\ddot{O} Z E T$}

Giriş: Pulmoner Kapak Yokluğu Sendromu (PKYS), Fallot tetralojisinin özelliklerini içeren, pulmoner kapağın fonksiyonel yokluğunun eşlik ettiği, pulmoner çıkış yolunda darlık ve yetersizlik sonucu ana pulmoner arter ve dallarinda anevrizmal dilatasyonun izlendiği bir kardiyak anomalidir.

Olgular: 2013-2014 yilları arasında prenatal dönemde PKYS tanisı konulan dört vakanın incelenmesi yapılmıştır.

Sonuç: PKYS'u nadir görülen bir kardiyak anomali olmasına rağmen tipik ultrason bulguları ile tanısı kolaydır. Dilate pulmoner arter ve dallarının akciğer dokusuna basisı sonucu gelişen bronkomalazi nedeniyle belirgin perinatal mortalite ve morbidite sahiptir.

Anahtar kelimeler: pulmoner kapak yokluğu sendromu, Fallot tetralojisi, kromozomal anomali, 22 11 mikrodelesyon, prenatal tanı, fetal sonuçlar.

\section{ABSTRACT}

Introduction: Absent pulmonary valve syndrome (APVS) is a variant of Tetralogy of Fallot (TOF). It shares the features of the classical form of TOF with the addition of incompetent or absent pulmonary valve. It is associated with severe dilatation of the main and branch pulmonary arteries because of concurrent severe pulmonary stenosis and regurgitation.

Cases: Four cases with a fetal diagnosis of APVS between 2013 and 2014 were analyzed.

Conclusion: APVS is easy to recognize with typical ultrasound images although it is a rare cardiac abnormality. It is associated with significant perinatal mortality and morbidity because of the bronchomalacia secondary to bronchial compression of the dilated pulmonary artery.

Key words: absent pulmonary valve syndrome, tetralogy of Fallot, chromosome abnormality, 22q 11 micro deletion, prenatal diagnosis, fetal outcomes.

\footnotetext{
İletişim Bilgileri:

Yazışmadan Sorumlu Yazar: Oya DEMIRCi

Yazışma Adresi: Zeynep Kamil Kadın ve Çocuk Hast.

Eğitim ve Araştırma Hastanesi, İstanbul, Türkiye

E-mail: demircioya@gmail.com

Makalenin Geliş Tarihi: 24.12.2014

Makalenin Kabul Tarihi: 20.01.2015
}

\section{GİRIŞ}

Pulmoner Kapak Yokluğu Sendromu (PKYS), Fallot Tetralojisi’ (TOF) nin tüm özelliklerinin yanı sıra pulmoner kapağın fonksiyonel yokluğunun eşlik ettiği bir anomalidir ve TOF olgularının \%6-9'unda görülür (1). TOF'dan farklı olarak; ana pulmoner arter ve dallarında anevrizmal dilatasyon, pulmoner kapağın displastik veya rudimenter görünümü, duktal arter yokluğu ve sağ ventrikül dilatasyonu mevcuttur. PKYS'lu vakalarm ultrasonografik tanısı klasik TOF lu vakalardan daha kolaydir. Kromozomal bozuklukları sıktır (\%25) ve büyük kısmını 22q11 mikrodelesyonu oluşturur $(1,2)$. Prenatal tanı konulan vakalarda genetik ve ekstra kardiyak anomalilerle birliktelik daha sık ve defekt boyutunun büyük olması nedeniyle prognoz daha kötüdür $(1,2)$. Bu çalışmada prenatal tanı konulan PKYS'lu olgularımızın fetal kardiyak bulguları, kalp dişındaki anomalileri, kromozomal bozukluları, prenatal ve postnatal izlem sonuçlarının değerlendirilmesi amaçlanmıştır.

\section{YÖNTEM}

2013-2014 y1lları arasında Zeynep Kadın ve Çocuk Hastalıları Eğitim ve Araştırma Hastanesi Perinatoloji Kliniğinde; ikinci ve üçüncü trimesterde fetal ekokardiyografi ile PKYS tanısı konulan 4 olgu çalışmaya alındı. Terminasyon uygulanan 1 olgu dişında tüm diğer olgularda postnatal ekokardiyografi ile PKYS tanıs1 doğruland1. Ultrasonografik incelemeler Voluson 730 Pro (GE Healthcare, Milwaukee, WI) ile yapıld1. Tüm olgularda kromozomal analizi ve 22q11 mikrodelesyonu için fluorescent in-situ hybridization (FISH) testi yapıldı.

\section{BULGULAR}

PKYS olgularının (n: 4) tanısı ortalama 26. gebelik haftasinda konuldu. Bir olguda 22q11 mikrodelesyonu saptand 1 ve 22. haftada gebelik termine edildi. İki olguda sağ akciğerde tip 3 kistik adenoid malformasyon ile uyumlu hiperekojen lezyon saptandi. Gebeliği devem eden 3 olgunun prenatal takiplerinde gelişme geriliği 
ya da kalp yetersizliği gelișmedi ve ortalama 38 haftalık iken doğum gerçeklești. Prenatal ultrasonda sağ akciğerde hiperekojenik lezyon saptanan $1 \mathrm{olgu}$, postnatal mekanik ventilatör desteğine rağmen 15 . dakikada solunum yetmezliği nedeniyle kaybedildi. Prenatal ultrasonda hiperekojenik lezyon olmamasına rağmen diğer bir olguda da solunum sıkıntısı gelişti, dört günlük iken opere edildi, post op 14. günde solunum yetersizliğinden kaybedildi. Klinik ve ekokardiyografik bulguları göreceli diğerlerinden daha iyi olan ve son kontrolünde 11. aylik olan 3. bebek ise dört aylık iken opere edildi. Ameliyatta VSD yamayla kapatıldı, sağ ventrükül pulmoner arter arasına conduit yerleştirildi ve bilateral pulmoner arter plikasyonu yapıldı.

\section{TARTIŞMA}

PKYS tipik ultrasonografik bulguları olan, pulmoner çıkış yolunda hem darlık hemde yetersizliğin bir arada bulunduğu bu nedenle sağ ventrikülde hem basınç hem de volüm yüklenmesi gelişen doğumsal kalp hastalığıdır. Sağ ventriküldeki bu volüm yüklenmesi ve yüksek pulmoner vasküler direnç ana pulmoner arter ve dallarında belirgin dilatasyona neden olur(3). Akciğer dokusuna bası yapan dilate olmuş pulmoner arterler, akciğer dokusunun gelişimde bozukluklara ve bronkomalaziye neden olabilmektedir (3-5). Akciğerde tip 3 kistik adenoid malformasyonu olan yenidoğanda bu akciğer patolojisinin dilate sağ pulmoner arterin baskısı sonucu olduğu düşünülmüştür. Kalp aksı bu malformasyona ikincil ileri derecede sola kaymıștı. Bu olgu postnatal 15. dakikada mekanik ventilasyon uygulanmasina rağmen solunum yetersizliğinden kaybedildi. Diğer olguda ise akciğerde ultrasonografi ile belirlenebilen bir patoloji olmamasına rağmen solunum yetersizliği gelişmiş, postop erken dönemde ve 18 günlük iken kaybedildi. PKYS'lu olup bronkomalazi gelișen bebeklerde prognoz daha kötü seyirlidir $(3,4)$. Her ikiside yenidoğan döneminde kaybettiğimiz bebeklerin klinik bulgularını dikkate aldığımızda ölüm nedeninin kardiyak nedenden ziyade bronkomalazi ikincil solunum yetersizliğinin ön planda olduğunu düşündürmektedir. Bronkomalazinin şiddetini gösteren tipik prenatal ultrasonografik bir bulgu mevcut değildir. Ancak bir olgumuzda olduğu gibi genişlemiş pulmoner arter ve dallarının basısına bağlı gelișen bronşların oklüzyonuna ikincil hiperekojenik kitlenin oluştuğu ve bu kitlenin kalbi ileri derecede itmesiyle kontrolateral akciğer dokusunda yaptığı basının doğum sonrasi solunum yetersizliğine neden olduğu kanısındayız. Diğer kaybedilen vakada ise benzer görüntü saptanmadi. Bununla birlikte her iki olguda yenidoğan döneminde solunum yetersizliğinin gelişmesi, bebeklerde şiddetli bronkomalazinin mevcut olduğunu düşündürmektedir. Yenidoğan döneminde solunum desteğine gereksinimini olan PKYS'lu bebeklerde mortalitenin daha yüksek olduğu belirtilmiştir $(3,6)$. TOF ile pulmoner kapak yokluğunun birlikteliği en sik $(\% 80)$ görülen PKYS tipi olup hemen her zaman duktal arter yokluğu ile beraberdir (3). Bu olgularda duktus arterizous olsaydı masif aortapulmoner şant gelişeceği ve bunun biventriküler büyümeye yol açacağ 1 ve yaşamla bağdaşmayacağı ileri sürülmektedir (3). Bu genel kuralla uyumlu olarak bizim 4 olgumuzda da duktus arteriozus mevcut değildi. Ayrıca, PKYS'lu olgularda 22q11 mikrodelesyonuna sik $(\% 20-25)$ rastlanmaktadir. Bizim sunduğumuz 4 olgunun birinde de 22q11 mikrodelesyonunu saptadik. 22q11 mikrodelesyonu ile ilişkili sendromlardaki malformasyonların hepsi 3 ve 4 . faringeal arklardan gelişen anatomik yapıları içerir. Burada altta yatan olay nöral krest hücrelerinin gelişiminde ve faringeal arka göçünde arrest olmasıyla ilişkilidir. Pulmoner kapak yokluğu ve duktal arter yokluğunun nöral krest hücrelerindeki yetersizlik nedeniyle olduğu belirtilmektedir (7). TOF'la birlikte olmayan pulmoner kapak yokluğunun diğer tiplerinde duktus arteriozus mevcuttur ve kromozom bozuklukları daha nadirdir (1, $3,8)$. İzole pulmoner kapak yokluğu olgular1 ise çoğunlukla asemptomatiktir $(1,3,8)$. PKYS'nun nadir görülmesi nedeniyle prenatal tanı konulan olgularda klinik prezantasyon ve seyirine ilişkin bilgiler oldukça sınırlıdır. PKYS ile ilgili son iki dekata ait literatür taraması değerlendirildiğinde fetal ve postnatal sağ kalım oranlarının oldukça düşük olduğu görülmektedir (2,9-10). Bu düşük sağ kalım oranları; gebelik terminasyonu, fetal kalp yetersizliği, solunum yetersizliği ve kromozomal anomalilerle ilişkilidir. Bununla birlikte son çalışmalarda; solunum desteği gereksinimi olmayan ve term doğan bebeklerde operasyon sonrası sağ kalım oranlarının klasik TOF'lu bebeklerden farkl1 olmadığını vurgulanmaktadır $(3,4)$. Sonuç olarak; PKYS tipik ultrasonografik bulgularıyla prenatal tanisı kolay olan, kromozomal ve ekstra kardiyak anomali riski yüksek olan oldukça nadir konotrunkal doğumsal kalp hastalığıdır. Postnatal erken veya ameliyat öncesi solunum desteğine gereksinim duyan bebeklerde prognoz kötü seyirlidir. Prenatal ultrasonografik incelemede hiperekojenik akciğer dokusu, kalbin ileri derecede itilmesi gibi bulguların varlığ1nın postnatal dönemde olası solunum desteği gereksinimini ve kötü prognoz hakkında bilgi sağlayabilir. Ancak bu çıkarımın büyük olgu serileriyle desteklenmesi gerektiği kanısındayız. 
Tablo 1. Olguların demografik ve klinik özellikleri.

\begin{tabular}{|c|c|c|c|c|c|c|}
\hline Olgular & $\begin{array}{c}\text { Prenatal } \\
\text { tanı haftası }\end{array}$ & $\begin{array}{c}\text { Kromozom } \\
\text { anomalisi }\end{array}$ & $\begin{array}{c}\text { Doğum } \\
\text { Haftası }\end{array}$ & $\begin{array}{l}\text { Doğum } \\
\text { ağırlığı }\end{array}$ & $\begin{array}{c}\text { Ekstrakardiyak } \\
\text { anomali }\end{array}$ & Prognoz \\
\hline 2. olgu & 22 & $\begin{array}{c}\text { 22q11 mikro- } \\
\text { delesyonu }\end{array}$ & 22 & - & $\begin{array}{c}\text { Sağ akciğerde } \\
\text { hiperekojenik kitle }\end{array}$ & Terminasyon \\
\hline 3. olgu & 26 & normal & 38 & 2950 & $\begin{array}{c}\text { Sağ akciğerde } \\
\text { hiperekojenik kitle }\end{array}$ & $\begin{array}{c}\text { Postnatal 15. dk } \\
\text { exitus } \\
\text { Mekanik ventilatör } \\
\text { gereksinimi }\end{array}$ \\
\hline 4. olgu & 26 & normal & 37 & 2600 & $\begin{array}{c}\text { 4. günde operas- } \\
\text { yon, postnatal 18. } \\
\text { günde exitus } \\
\text { Mekanik ventilatör } \\
\text { gereksinimi }\end{array}$ \\
\hline & & normal & 39 & 3030 & Yok & $\begin{array}{c}\text { Y. ayda operasyon, } \\
\text { 11 aylık, sağ }\end{array}$ \\
\hline
\end{tabular}

\section{KAYNAKLAR}

1. Paladini D, Volpe P. Ultrasound of Congenital Fetal Anomalies, Differential Diagnosis and Prognostic Indicators. Second Edition. Page 201-3.

2. Volpe P, Paladini D, Marasini M, Buonadonna AL, Russo MG, Caruso G, Marzullo A, Arciprete P, Martinelli P, Gentile M. Characteristics, associations and outcome of absent pulmonary valve syndrome in the fetus. Ultrasound Obstet Gynecol. 2004;24:623-8.

3. Wertaschnigg D, Jaeggi M, Chitayat D, Shannon P, Ryan G, Thompson M, Yoo SJ, Jaeggi E. Prenatal diagnosis and outcome of absent pulmonary valve syndrome: contemporary single-center experience and review of the literature. Ultrasound Obstet Gynecol. 2013;41:162-7.

4. Mivelaz Y, Lim KI, Templeton C, Campbell AI, Potts JE, Sandor GG. Population-based review of tetralogy of Fallot with absent pulmonary valve: is prenatal diagnosis really associated with a poor prognosis? Ultrasound Obstet Gynecol. 2012;40:536-41.
5. Güven F, Kavas E, Kavas R, Gökyayla N, Erbil $N$, Say A. Pulmoner kapak yokluğu ile birlikte olan fallot tetralojili bir olgu. Zeynep Kamil Tıp Bülteni 2002;33:52-3

6. Saylam GS, Sarıoğlu A, Beşikçi R, Batmaz G, Kınoğlu B, Sarıoğlu T. Pulmoner Kapak Yokluğu Sendromu: 15 Olgunun Analizi. Türk Kardiyol Dern Arş 1997;25:93-100.

7. Momma K. Cardiovascular anomalies associated with chromosome 22q11.2 deletion syndrome. Am J Cardiol. 2010; 105:1617-24.

8. Grewal DS, Chamoli SC, Saxena S. Absent pulmonary valve syndrome - Antenatal diagnosis. Med J Armed Forces India. 2014; 70:198-200.

9. Galindo A, Gutiérrez-Larraya F, Martínez JM, Del Rio M, Grañeras A, Velasco JM, Puerto B, Gratacos E. Prenatal diagnosis and outcome for fetuses with congenital absence of the pulmonary valve. Ultrasound Obstet Gynecol. 2006;28:32-9.

10. Razavi RS, Sharland GK, Simpson JM. Prenatal diagnosis by echocardiogram and outcome of absent pulmonary valve syndrome. Am J Cardiol. 2003; 91:429-32. 